\title{
Endoscopy training in Korea
}

\author{
Joon Sung Kim and Byung-Wook Kim
}

Division of Gastroenterology, Department of Internal Medicine, College of Medicine, Incheon St. Mary's Hospital, The Catholic University of Korea, Incheon, Korea

Received: January 22, 2019 Accepted: February 5, 2019

\section{Correspondence to}

Byung-Wook Kim, M.D.

Division of Gastroenterology, Department of Internal

Medicine, College of Medicine, Incheon St. Mary's Hospital,

The Catholic University of Korea, 56 Dongsu-ro, Bupyeong-gu,

Incheon 21431, Korea

Tel.: +82-32-280-5051

Fax: $+82-32-280-5082$

E-mail: gastro@catholic.ac.kr

This paper was contributed by The Korean Society of Gastrointestinal Endoscopy.
It is essential to maintain high-quality endoscopy given the increasing number of endoscopic screens performed in Korea. The training of fellows to perform endoscopies is challenging. The rapid development of endoscopic techniques and rising patient complexity increase the training pressures. At the end of training, all practitioners must perform endoscopy safely and effectively. Here, we examine the current status of endoscopy training in Korea. Although our system produces many competent endoscopists, there is room for improvement. Formal training programs should be developed to train the trainers. Specific assessment tools measuring performance and improving training are required. Changes should be made at all levels to improve our endoscopy training system.

Keywords: Endoscopy; Education; Competency-based education

\section{INTRODUCTION}

Endoscopic services are readily available in Korea, and the annual number of endoscopies is increasing [1]. It is essential to maintain high-quality endoscopy given the increasing number of endoscopic screens performed. Training in terms of routine procedures (esophagogastroduodenoscopy and colonoscopy) is usually imparted during gastroenterology programs 1 to 2 years in duration taken during a fellowship. The Korean Society of Gastrointestinal Endoscopy (KSGE) established goals and guidelines for trainee education in 2011 and recently updated them [2]. In 2018, 372 fellows commenced training in KSGE-certified programs, and 370 doctors applied to join the subspecialty board of gastrointestinal endoscopy. The training of fellows to perform endoscopies is challenging. The training responsibilities fall upon individual program directors and their faculties. Usually, trainees study under one or two experienced endoscopists during their fellowships. Most experts lack formal training on how to teach endoscopy. Competency in endoscopy is currently confused with the ability to teach endoscopy; experience is not always accompanied by good teaching skills [3]. This is an important limitation of Korean training programs. Gastroenterology units should strive to ensure that trainees can perform esophagogastroduodenoscopy safely and effectively upon completion of training. Training programs should also include the principles of sedation/analgesia, how to obtain informed consent, and medical ethics [4]. Here, we discuss the current limitations of endoscopy training programs in Korea. 
We also make practical suggestions for improvement.

\section{CURRENT STATUS OF ENDOSCOPY TRAINING IN KOREA}

Currently, endoscopy training features an apprenticeship model. Trainees first observe and then assist experts performing various procedures. Then, trainees perform endoscopies on real patients with or without expert supervision. Trainees are expected to achieve a certain level of competency after a given number of endoscopies. This approach has the advantage that expert supervision and feedback are available. However, several limitations are apparent. First, one or two expert endoscopists are responsible for teaching and performing competency assessments of all trainees. Expert endoscopists are not compelled to receive education on how to teach. Second, training usually takes place during the clinical practice of experts, who are thus usually overloaded. Formal training curricula are lacking, and the level of training depends largely on the hospital hosting the trainee. Third, patients are exposed to discomfort and increased risks of adverse events until the trainee gains a sufficient level of competency.

\section{HOW TO CHANGE ENDOSCOPY TRAINING IN KOREA}

Korea lacks a universal, comprehensive endoscopy teaching curriculum. Currently, overall trainee competency is gaged by their procedural volumes and subjective evaluations. Future training should focus on assessment of specific metrics and individual abilities [5]. This requires development of a new, formal, endoscopy teaching curriculum that clarifies the training goals, instruction methods, and assessment tools. An ideal training program should combine an online curriculum with assessment, live courses featuring handson training with formative evaluation and feedback, and post-training assessment of skills and knowledge [3]. These programs should optimize both the cognitive and technical skills required by endoscopists [6].

\section{DEVELOPMENT OF TRAINERS AND TRAINING PROGRAMS}

Dividing an endoscopic technique into individual parts that are then comprehensively described is an essential feature of training. However, most trainers in Korea have never received formal training in teaching. Although most trainers want to be good teachers, many find it easier to demonstrate a procedure rather than to describe the constituent steps. Thus, formal training programs should aim to train the trainers in defining the components of endoscopic procedures and describing them to trainees. Trainers should be trained in assessment of trainee expertise and how to individualize the training of each trainee. Ideally, improving trainer quality should facilitate and shorten the duration of training.

\section{ASSESSMENT OF ENDOSCOPY TRAINING}

Currently, trainee endoscopic skills are assessed based on the number of procedures performed and a qualifying examination [7]. Although these methods have produced excellent endoscopists, the assessment tools require improvement. The tools should objectively assess both trainer and trainee competence. Recently, researchers in Western countries have described several tools for assessment of endoscopic skills [8-10]. However, it is difficult to simply apply these indicators in Korea, because the disease prevalence differs greatly from that of Western countries. Simply measuring performance can improve endoscopic quality [11]. The KSGE recently published a revised version of endoscopic quality indicators for Korea [7]. However, the new edition still regards the number of procedures and the duration of education as markers of competency.

We need to develop specific tools measuring endoscopic performance to better train trainees. These tools should be simple and capable of being applied feasibly and regularly during clinical practice. Assessment of trainee performance would allow the various training programs to be compared. This should increase the general quality of endoscopists. The tools can also be used to help maintain the performance of clinical practitioners who have completed training. 


\section{DEVELOPMENT OF TRAINING DEVICES}

Simulator-based training has not been generally accepted in Korea; most clinical skills are acquired by directly practicing on patients. Many studies have shown that simulators improve skills and shorten the time taken to acquire competency, particularly during the early stages of training [12,13]. Simulators can also be used to assess trainee skills and competency [14]. Recently, box models of endoscopic simulators have been used in some Korean hospitals to train novice endoscopists. Some studies found that these devices rapidly improved skills $[13,15]$. Although the simulators may not reproduce the actual endoscopic experience, they facilitate the learning of specific endoscopic techniques such as how to handle the scope. Simulator-based training has reduced colonoscopy completion times and imparted better technical skills than has patient-based training [16]. Formal programs should be developed using these simulators; their widespread employment may shorten the learning process. In the future, virtual simulators and three-dimensional-printed organs may also be used for training $[17,18]$. Currently, such devices are rarely employed in most Korean training hospitals. We must become familiar with the simulators and prepare curricula incorporating their use.

\section{SEDATION TRAINING}

Malpractice claims based on sedation-related complications are frequently reported in the media. We suspect that such claims constitute a significant proportion of medicolegal cases brought against Korean gastroenterologists. Therefore, future endoscopy training should include sedation practice [19]. Formal educational programs and tests are required to improve sedation competence. Trainees should be educated in pre-procedural patient assessment and preparation and patient monitoring during endoscopy [20]. They should be familiar with the doses and timings of the medications administered during the procedure. Trainees should also be trained in the management of adverse events and post-procedural patient monitoring [21]. Although data are lacking, most trainees receive little education on sedation during their fellowships. The KSGE pro- vides both online training aids and formal training programs. However, these programs are not readily assessable; no validated method by which competency can be assessed is available. A systematic, thorough training program should be developed, along with methods measuring competency.

\section{FUTURE ASPECTS OF ENDOSCOPY TRAINING}

Endoscopic technology is developing rapidly. Both trainees and trainers require regular updates on advances in endoscopic techniques. Image-enhanced endoscopy employing narrow-band imaging, flexible spectral imaging color enhancement, and the i-Scan were introduced in the early 2000 s for diagnosis of gastrointestinal lesions [22,23]. Linked color imaging and blue laser imaging systems are the latest modalities that usefully identify upper gastrointestinal lesions [24]. These new imaging modalities greatly facilitate the diagnosis of gastrointestinal lesions and will become popular in the future [25]. Trainees must be familiar with the rapid developments in image-enhanced endoscopy.

Obesity now affects $13 \%$ to $39 \%$ of adults worldwide [26]. Endoscopic bariatric therapies have recently been developed to treat obesity [27]; these are not routinely included in training, but trainees should be familiar with the procedures. Training programs should include various management options for obesity (lifestyle therapies, medications, and bariatric endoscopy).

In the future, a fundamental shift in endoscopy training may be required given the developments in augmented, virtual, and mixed realities. Such technologies offer virtual environments indistinguishable from the real world [28]. VR has already been applied during surgery, reducing operative times and increasing overall performance [29]. Such technologies may allow trainees to practice endoscopy in a three-dimensional environment similar to that of real patients [30]. Although these technologies are currently not widely used in Korea, we should be prepared for future changes.

\section{CONCLUSIONS}

In recent years, the focus of endoscopy training has 
shifted away from the current time-based programs toward competency-based programs, based on the premise that trainees require high-quality training before they can perform high-quality endoscopy [31]. Korean endoscopists are subjected to increased public awareness and growing legal pressure. We must ensure that graduating trainees can perform endoscopy safely and effectively. The rapid developments in endoscopic techniques and increased patient complexity add to the pressure to educate trainees well. To date, no standard training method is available. A national training program/curriculum is required. Assessment tools objectively measuring performance should be used to ensure the competency of those who complete the programs. Improvement in our current training system will require effort, as changes are required at all levels.

\section{Conflict of interest}

No potential conflict of interest relevant to this article was reported.

\section{REFERENCES}

1. Cho YK. How to improve the quality of screening endoscopy in Korea: national endoscopy quality improvement program. Clin Endosc 2016;49:312-317.

2. Moon HS, Choi EK, Seo JH, et al. Education and training guidelines for the board of the Korean society of gastrointestinal endoscopy. Clin Endosc 2017;50:345-356.

3. Waschke KA, Coyle W. advances and challenges in endoscopic training. Gastroenterology 2018;154:1985-1992.

4. Kim JS, Kim BW. Training in endoscopy: esophagogastroduodenoscopy. Clin Endosc 2017;50:318-321.

5. Frank JR, Snell LS, Cate OT, et al. Competency-based medical education: theory to practice. Med Teach 2010;32:638645 .

6. Biswas S, Alrubaiy L, China L, et al. Trends in UK endoscopy training in the BSG trainees' national survey and strategic planning for the future. Frontline Gastroenterol 2018;9:200-207.

7. Min JK, Cha JM, Cho YK, et al. Revision of quality indicators for the endoscopy quality improvement program of the national cancer screening program in Korea. Clin Endosc 2018;51:239-252.

8. Sedlack RE. The mayo colonoscopy skills assessment tool: validation of a unique instrument to assess colonoscopy skills in trainees. Gastrointest Endosc 2010;72:1125-1133.

9. Fried GM, Marks JM, Mellinger JD, Trus TL, Vassiliou MC, Dunkin BJ. ASGE's assessment of competency in endoscopy evaluation tools for colonoscopy and EGD. Gastrointest Endosc 2014;80:366-367.

10. Coyle WJ. Developing tools for the assessment of the learning colonoscopist. Gastrointest Endosc 2014;79:808810.

11. Imler TD, Imperiale TF. Measuring the quality of colonoscopy: where are we now and where are we going? Gastrointest Endosc 2015;82:520-522.

12. Dawe SR, Windsor JA, Broeders JA, Cregan PC, Hewett PJ, Maddern GJ. A systematic review of surgical skills transfer after simulation-based training: laparoscopic cholecystectomy and endoscopy. Ann Surg 2014;259:236-248.

13. Blackburn SC, Griffin SJ. Role of simulation in training the next generation of endoscopists. World J Gastrointest Endosc 2014;6:234-239.

14. Walsh CM, Sherlock ME, Ling SC, Carnahan H. Virtual reality simulation training for health professions trainees in gastrointestinal endoscopy. Cochrane Database Syst Rev 2012;6:CDoo8237.

15. Jirapinyo P, Kumar N, Thompson CC. Validation of an endoscopic part-task training box as a skill assessment tool. Gastrointest Endosc 2015;81:967-973.

16. Jang HJ. Training in endoscopy: colonoscopy. Clin Endosc 2017;50:322-327.

17. Harpham-Lockyer L, Laskaratos FM, Berlingieri P, Epstein O. Role of virtual reality simulation in endoscopy training. World J Gastrointest Endosc 2015;7:1287-1294.

18. Holt BA, Hearn G, Hawes R, Tharian B, Varadarajulu S. Development and evaluation of a 3D printed endoscopic ampullectomy training model (with video). Gastrointest Endosc 2015;81:1470-1475.

19. Da B, Buxbaum J. Training and competency in sedation practice in gastrointestinal endoscopy. Gastrointest Endosc Clin N Am 2016;26:443-462.

20. Yoon SB, Cho YS. Sedation for gastrointestinal endoscopy: practical issues in patient safety and quality management. Clin Endosc 2016;49:1-3.

21. American Association for Study of Liver Diseases; American College of Gastroenterology; American Gastroenterological Association Institute, et al. Multisociety sedation curriculum for gastrointestinal endoscopy. Gastrointest Endosc 2012;76:e1-e25. 
22. Osawa H, Yoshizawa M, Yamamoto H, et al. Optimal band imaging system can facilitate detection of changes in depressed-type early gastric cancer. Gastrointest Endosc 2008;67:226-234.

23. Yao K, Oishi T, Matsui T, Yao T, Iwashita A. Novel magnified endoscopic findings of microvascular architecture in intramucosal gastric cancer. Gastrointest Endosc 2002;56:279-284.

24. Osawa H, Miura Y, Takezawa T, et al. Linked color imaging and blue laser imaging for upper gastrointestinal screening. Clin Endosc 2018;51:513-526.

25. Osawa H, Yamamoto $H$. Present and future status of flexible spectral imaging color enhancement and blue laser imaging technology. Dig Endosc 2014;26 Suppl 1:105-115.

26. Igel LI, Kumar RB, Saunders KH, Aronne LJ. Practical use of pharmacotherapy for obesity. Gastroenterology 2017;152:1765-1779.
27. Jirapinyo P, Thompson CC. Training in bariatric and metabolic endoscopic therapies. Clin Endosc 2018;51:430438.

28. Hann A, Walter BM, Mehlhase N, Meining A. Virtual reality in GI endoscopy: intuitive zoom for improving diagnostics and training. Gut 2018 Sep 18 [Epub]. https://doi. org/10.1136/gutjnl-2018-317058.

29. Lin CJ, Cheng CF, Chen HJ, Wu KY. Training performance of laparoscopic surgery in two- and three-dimensional displays. Surg Innov 2017;24:162-170.

30. Bhushan S, Anandasabapathy S, Shukla R. Use of augmented reality and virtual reality technologies in endoscopic training. Clin Gastroenterol Hepatol 2018;16:16881691.

31. Siau K, Hawkes ND, Dunckley P. Training in endoscopy. Curr Treat Options Gastroenterol 2018;16:345-361. 